\title{
Las condiciones de la urbanización y la producción de naturaleza en ciudades litorales chilenas. Los casos de Valparaíso y Coquimbo
}

Rodrigo Hidalgo. Pontificia Universidad Católica de Chile, Santiago, Chile.

Carlos Vergara-Constela. Pontificia Universidad Católica de Chile, Santiago, Chile. Miguel González-Rodríguez. Pontificia Universidad Católica de Chile, Santiago, Chile.

RESUMEN | A través de un método descriptivo general (análisis documental, estadísticas de población y vivienda, y la observación), en el artículo se examina el proceso de urbanización y su relación con la naturaleza en ciudades costeras chilenas, tomando como ejemplos las comunas litorales de Coquimbo y Valparaíso. Mediante un marco conceptual asociado al paradigma marxista-urbano de la producción del espacio, se caracteriza y analiza ambas comunas, dando cuenta de las formas que ha adquirido la relación entre el entorno construido y la naturaleza, centrándonos principalmente en el papel de la vivienda y, en específico, de la vivienda subsidiada. Se concluye demostrando el proceso contradictorio de urbanización en el que se encuentran ambas comunas.

PALABRAS CLAVE | urbanización, vivienda, morfología urbana.

ABSTRACT | Through a general descriptive method (documentary analysis, population and housing statistics, and observation), this article analyzes the urbanization process and its relationship with nature in Chilean coastal cities, using as case studies the coastal communes of Coquimbo and Valparaiso. Through a conceptual framework associated with the Marxist-urban paradigm of the production of space, both communes are characterized and analyzed, accounting for the forms that the relationship has acquired between the built environment and nature, focusing mainly on the role of housing and, specifically, of subsidized housing. It concludes by demonstrating the contradictory urbanization process in which both communes are found.

KEYWORDS | urbanization, housing, urban morphology.

Recibido el 7 de diciembre de 2020, aprobado el 17 de abril de 2021.

E-mails: R. Hidalgo, rhidalgd@uc.cl |C. Vergara-Constela, cdvergara1@uc.cl| M. González-Rodríguez,mfgonzalez13@uc.cl 


\section{Introducción}

Los frentes litorales marinos, fluviales y lacustres han tenido una relación dispar con el desarrollo de las ciudades. En el caso del continente americano, por ejemplo, se establece una clara diferencia entre las costas del Pacífico y del Atlántico, cuestión dada esencialmente por las condiciones geomorfológicas presentes en dichos espacios (Bittar, 2016). A esa condición se suman otros aspectos esenciales que influyen en el proceso de urbanización, como el sitio, entendido como la pendiente establecida por la topografía, hidrografía, vegetación y clima, entre los más relevantes (Gray de Cerdán, 1987).

Las ciudades chilenas continentales sobre el Pacífico ostentan una condición de sitio que las caracteriza, donde la planicie litoral se encajona sobre la formación orográfica que configura la cordillera de la Costa (Castro, 2015). En muchos casos -como Valparaíso y Coquimbo-, la desembocadura de cursos de agua modela el paisaje litoral, cruzando las formaciones heredadas de la acción marina por la escorrentía superficial, dando lugar a un entramado de quebradas que han sido rellenadas a lo largo de los ańos para la actividad humana de residencia, ocio o cultivos agrícolas, entre otros usos (Bodini, 1985; Castro \& Hidalgo, 2002).

La producción de naturaleza sitúa esta problemática en la renta y apertura de frentes de explotación en diferentes mercados, que van desde la agricultura hasta la vivienda, entre varios. Para Reclus (1975), esto resulta plausible en tanto la humanidad ha adquirido una conciencia sobre la naturaleza como algo externo. Para el pensador francés, se trataría de una naturaleza secundaria que transforma la naturaleza primigenia con afanes de renta y de reproducción capitalista. Esta segunda naturaleza, construida y puesta en valor, cuestiona conceptos que cruzan lo urbano y sus estructuras materiales en la ciudad.

Los rellenos de terrenos de pendiente y de áreas inundadas constituyen una realidad en muchas ciudades del mundo (Boer, 2020). Valparaíso y Coquimbo nuestros casos de estudio- ostentan innumerables ejemplos de estas prácticas ancestrales en la relación entre seres humanos y superficie terrestre. No solo es un modo de producir ciudad ganando terrenos para ello, también es una forma de producir naturaleza: creando la quebrada, inventando un paisaje, aplanando un terreno o promocionando un estilo de vida "sustentable".

A simple vista podemos señalar que las ciudades litorales de la costa del Norte Chico, centro y centro sur de Chile, poseen una condición similar en sus patrones de crecimiento y riesgos asociados. Sus formas de urbanización han decantado en condiciones de vulnerabilidad, evidenciadas - por ejemplo- en los terremotos de 2010 y 2015 (Martínez, 2014). Coquimbo y Valparaíso son dos ciudades-puerto que tienen un origen y evolución particular asociados a la actividad portuaria, cumpliendo un rol nodal tanto respecto de su propio núcleo urbano, como de la región y el país en general. Como espacios comunales, ambas forman parte de una conurbación costera, donde Valparaíso se constituye en capital regional de la Quinta Región de Chile y Coquimbo, por su parte, es la segunda comuna más relevante de la Cuarta Región del país en materia de población y funciones administrativas y públicas. De todos modos, dado que la función portuaria ha tenido un 
peso histórico en la estructuración urbana, la relación con el desarrollo urbano ha sido un detonante para que ambas ciudades se hayan constituido en núcleos con peso regional. En ellas, actualmente la función portuaria continúa siendo clave en la inversión de infraestructura de mayor escala, modificando su morfología, sobre todo a través de obras viales que han transformado la accesibilidad y conectividad hacia el borde costero.

Tanto la condición de sitio como la funcionalidad de Valparaíso y Coquimbo han trazado una herencia inconfundible, cuestión que plantea la necesidad de discutir cómo, en términos conceptuales y operativos, estos aspectos se friccionan con las dinámicas urbanas actuales, sobre todo en relación con un problema acuciante, como es el relativo a la vivienda. Así, considerando su condición de ciudades litorales y portuarias, donde los sistemas de terrazas fluviales y marinas dan a lugar a un anfiteatro natural en que se emplaza la vida, el artículo tiene por objetivo discutir el proceso de urbanización y su relación con la naturaleza en ciudades litorales chilenas, tomando como casos de estudio a Coquimbo y Valparaíso.

\section{Aires de naturaleza en la producción del espacio residencial en ciudades litorales}

La urbanización se encuentra íntimamente relacionada con los ciclos de acumulación, producción y reproducción de capital. Para Lefebvre (2013), puede ser comprendida como la materialización del modo de producción capitalista en tanto el valor de cambio se superpone al valor de uso, donde la producción de espacio expresa las contradicciones de la sociedad. Para Milton Santos (1990), la urbanización es entendida como un resultado que se desprende de las formas de especialización productivo-capitalistas del espacio, donde la acumulación de excedente tiende a ser reinvertida en entorno construido, aunque no necesariamente en el mismo espacio en que se acumula. Santana (2018) precisa señalando que la urbanización es un proceso contradictorio de producción y reproducción de formas, funciones y estructuras urbanas.

Neil Smith (2020) planteó la necesidad teórico-política de poner a la naturaleza y al espacio en un mismo estatus ontológico. Solo su homologación podría restituir la posibilidad de investigar en profundidad lo que él denomina dialéctica geohistórica de la coproducción entre naturaleza y espacio. Esta postura le permite hacer una crítica a Henri Lefebvre. Para Smith, Lefebvre logró romper con la idea newtoniana de espacio abstracto para ponerlo en el lugar de un artefacto maleable y, por lo tanto, producible y reproducible; sin embargo, no logró romper con la concepción tradicionalista de la naturaleza, la cual solo tiene lugar dentro del espacio.

De todas maneras, el trabajo de Lefebvre (2013) es prolífico para entender la urbanización contemporánea y la sobrevivencia de la producción capitalista en el espacio urbano. Por lo mismo, sostenemos que el espacio y su producción son fundamentales para entender el modo en que se transforma la materia, se producen simbolismos y se entrecruzan relaciones de poder entre distintos actores y agentes sociales. Sobre esto, Smith (2020) ha planteado que generalmente tendemos a apreciar la naturaleza como lo opuesto a la producción, es decir, como algo imposible de 
ser producido. Sin embargo, la producción ineludiblemente altera la forma previa de la naturaleza, por lo que comprender la naturaleza como externa y opuesta a la sociedad resulta inoperante. Dicho de otra manera, lo que apreciamos como una base natural no es más que el resultado de la producción social; por tanto, si ubicamos al "paisaje natural" en contexto histórico, indefectiblemente lo veremos en constante disputa, como medio y proceso de producción. En esta lógica, el pensamiento marxista ha develado el rol de la producción capitalista basado en la explotación de lo que la naturaleza ofrece como recurso, por lo que ella adquiere el estatus de medio de producción universal.

Considerando lo anterior, la interacción entre lo natural y lo social en un marco de producción capitalista se basa en una relación estructurada por un potencial valor de cambio. Lo podemos ver en la producción de comida orgánica, en la industria del reciclaje, en los discursos sobre la sostenibilidad o en la vivienda que se promociona por su cercanía al mar o al bosque. Tal como señala Smith (2020), la producción del espacio es un corolario de la producción de la naturaleza, donde lo que podemos llegar a establecer como una diferencia entre la primera y segunda naturaleza en la modernidad, solo tiene razón de ser como una diferencia entre los mundos no humanos y los que son creación humana, en sentido material y cultural. Entonces, podemos fijar la producción de naturaleza en el cruce entre urbanización, sus condiciones y posibilidades materiales, y las relaciones sociales asociadas a elementos fijados por el medio o sustrato físico del emplazamiento. Indefectiblemente, la producción de naturaleza está vinculada con el concepto de condición de sitio, que enfatiza la forma en que las capas de la naturaleza -como la hidrografía, biogeografía y geomorfología, entre otros- establecen un marco de relaciones dialécticas con la forma urbana (Gray de Cerdán, 1987).

Por el motivo seńalado, el cruce entre la urbanización como apertura de nichos de renta, y la naturaleza como frontera y límite en movimiento, es un eje clave en la producción de lo urbano. Es en este marco que en ciudades costeras, emplazadas en costas escarpadas, con predominio mediterráneo y/o semidesértico, su condición de sitio impone barreras a la construcción material de la ciudad. El manejo de las aguas, los rellenos de quebradas y la ganancia constante de terrenos a zonas húmedas marinas son ejemplo de ello. Hasta fines del siglo pasado, las zonas húmedas aún eran lugares de depósito de desechos - de hecho, muchas lo siguen siendo-, con bajo control y regulación gubernamental (Rojas, Munizaga, Rojas, Martínez \& Pino, 2019). Esas zonas, antes denominadas pantanos o bofedales, son ahora humedales. En Placilla de Peńuelas (Valparaíso), por ejemplo, el viejo tranque La Luz, hoy es una laguna. Esta modificación metafórica sobre las condiciones naturales hoy son puestas en valor para la urbanización (Hidalgo, Rodríguez, Paulsen-Espinoza \& Alvarado, 2018). De esta manera, esas condiciones naturales de base son promocionadas por proyectos inmobiliarios, forma de producción que se vale de la ciudad bien servida y equipada para rentabilizar y servir de polea a los negocios inmobiliarios, aumentando con ello las posibilidades de extracción de renta del suelo (Lefebvre, 1974). Esto ocurre con las inversiones de mayor escala, donde estas amenidades/condiciones son incorporadas como paisaje de la oferta 
inmobiliaria o incluso formando parte del equipamiento mismo de tales proyectos (Hidalgo, Camus, Alvarado, Paulsen-Espinoza \& Olea, 2016).

Lo anterior, sin embargo, no constituye la única forma de producir naturaleza. Si bien los grupos medio-altos y altos optan por localizaciones de privilegio en términos de conectividad y paisaje natural, las clases populares ocupan terrenos donde las fronteras de la urbanización son más difíciles de traspasar. Aquí la presencia de quebradas y/o zonas inundables con escasa factibilidad de servicios sanitarios y de urbanización, es la tónica general de la producción de hábitat. Estos emplazamientos, más allá de su precariedad y estatus legal, tienden a valorizar y abrir frentes de urbanización, cuestión que ha sido descrita para el caso de las favelas en Brasil, donde la urbanización fue posibilitada por la producción informal de vivienda, pero luego aprovechada por la inversión de grandes capitales (Mautner, 1999; Pereira, 2005).

\section{La vivienda, la urbanización y la naturaleza}

En la actualidad, la vivienda se produce, distribuye y consume como una mercancía. Una de las funciones predominantes de su producción no tiene relación directa con la posibilidad de dar habitación y hogar a las personas, sino con dar fluidez a los problemas de estancamiento y sobreacumulación de capital (Harvey, 2012). Tal como lo planteó Lefebvre (1976) a mediados del siglo xx, los circuitos inmobiliarios, siempre ubicados en un lugar secundario respecto de los capitales productivos, han ido cobrando mayor protagonismo en la acumulación y reproducción del capital. ${ }^{1}$

El proceso de mercantilización de la vivienda implica situarla dentro de la clásica contradicción entre valor de cambio y valor de uso (Harvey, 2014; Hidalgo, Alvarado \& Santana, 2016; Madden \& Marcuse, 2019). Por un lado, la vivienda es clave como instrumento y mercancía destinada al beneficio económico; y, por otro, es el espacio donde se construye hogar, se pernocta y, en el caso nacional, donde también se depositan las esperanzas del porvenir y el progreso material (Alvarado, 2019). Como sabemos, el neoliberalismo chileno se ha basado en una profunda mercantilización de las relaciones sociales, donde los mecanismos de integración social fueron depositados en las posibilidades y accesos al consumo de bienes y servicios de diverso orden (Mayol, 2019). En esta lógica, bienes públicos como la educación, previsión, salud y vivienda han adquirido un estatus monetarizado y, por lo tanto, transable, acumulable y -cómo no- agotable.

El neoliberalismo chileno ha requerido de la tecnificación del Estado, más no su empequeñecimiento y pérdida de injerencia en los problemas públicos. Al contrario, tal como ha planteado Alvarado (2019), la presencia del Estado en el mercado es amplia en tanto permite dotar de protagonismo a determinados agentes en la provisión de bienes y servicios, estableciendo reglas del juego para la obtención de beneficios y generando regulaciones ad hoc a través de instrumentos de diversa índole. En este orden, el acceso a la vivienda ha representado un punto clave, convirtiéndose

1 En Santana (2019) y Rehner, Rodríguez y Murray (2018) se puede encontrar una discusión robusta sobre las nociones de segundo circuito de Henri Lefebvre y circuito secundario de David Harvey. 
en piedra angular dentro del proyecto ideológico del neoliberalismo. El fomento a la propiedad privada, frente a la necesidad de entregar soluciones habitacionales ante el creciente malestar social identificado ya desde mediados de los noventa (Mayol, 2012; Programa de Naciones Unidas para el Desarrollo [PNUD], 1998), han ubicado a la vivienda propia cómo símbolo de lo que Alvarado (2019) denomina "bienestar neoliberal". Esta contradicción posee una potencia inusitada, puesto que se incrusta en la retórica mítica de la casa propia como mecanismo de salida de la pobreza y, a la vez, se convierte en una potente mercancía para la acumulación de capital.

Para las clases populares y, en las últimas décadas, para los grupos medios, el instrumento clave de acceso a la vivienda ha sido el subsidio habitacional, el cual permite dinamizar mercados segmentados de vivienda según capacidad de ahorro y endeudamiento. La función subsidiaria del Estado se ha enfocado en la oferta. Esto implica que el empresariado de la construcción pueda definir no solo la tipología de las viviendas, sino su localización y, con ello, la forma de producción de espacio residencial (Hidalgo, 2005; Sugranyes, 2005). Lo que resulta palpable en términos materiales es la entrega, desde la década de 1980 hasta la actualidad, de una gran cantidad de viviendas en las principales ciudades chilenas. Los impactos espaciales pueden enmarcarse dentro de las clásicas descripciones de procesos de metropolización y/o conurbación (de Mattos, 2006; Fuentes \& Pezoa, 2018; Rojo Mendoza, Jara \& Frick, 2019) o en la destrucción y producción de naturaleza (Hidalgo, Rodríguez \& Alvarado, 2018; Vergara-Perucich, 2018) bajo un denominador común: la creación de nichos de acumulación de renta de suelo.

Este punto resulta determinante, puesto que la renta del suelo en la producción capitalista adquiere un carácter mistificado (Ramas, 2015). Esto quiere decir que la relación social que articula la extracción de renta se manifiesta de manera invertida: el suelo aparece como una fuente fija de ingresos, determinados en un precio, producto de la capitalización de una renta asociada a su propiedad. El problema que advierte Ramas (2015) es la invisibilización del trabajo productivo como fuente real de la producción de un plusvalor, lo que lo lleva a plantearse la pregunta sobre cómo el suelo, donde no hay objetividad social, puede entregar un valor, siendo que este se produce mediante el trabajo. Entonces, la relación social se manifiesta de manera cosificada en la relación con la naturaleza. Más aún, para Lefebvre (2015), esta lógica pasa más allá de la extracción intensa y el agotamiento de la renta extraíble desde un suelo determinado, para definirse a partir de la rarificación de bienes como el agua o la vegetación, cuestión que no es más que la expresión de una naturaleza apropiada, transformada y progresivamente destruida.

\section{Sobre la descripción geográfica}

El estudio de la relación entre producción de naturaleza y producción material del espacio urbano implica adoptar un posicionamiento que supere la aplicación de técnicas y procedimientos metodológicos de manera parcelada. Una postura que se encuentra en esta tónica es la descripción teóricamente informada (Lefebvre, 2015, pp. 231-252), la cual busca conjeturar las dimensiones de una totalidad mediante la puesta en relación de herramientas estadísticas, observación y discusión teórica 
entre el conocimiento ya producido y las teorías desde donde estamos interpretando la realidad (Tabla 1$)$.

A diferencia de la idea común que pone la descripción como una capa menor en cuanto a profundidad, pensamos que ella, como método para la geografía, es prolífico e inagotable, en tanto logra entramar de manera relacional las formas múltiples que adquiere el espacio (Zusman, 2014). En este sentido, resulta fundamental como método, no solo para ensamblar elementos "físicos" y "humanos", sino también para problematizar y sintetizar la experiencia de observar, las tendencias estadísticas y el análisis paisajístico. El método descriptivo contribuye a fortalecer la propuesta epistemológica de la producción social del espacio, como postura que restituye la totalidad entre naturaleza y sociedad (Smith, 2020).

TABLA I | Herramientas metodológicas

\begin{tabular}{|l|l|l|l|}
\hline HERRAMIENTA & \multicolumn{1}{|c|}{ VARIABLE } & \multicolumn{1}{|c|}{ FUENTE } & \multicolumn{1}{c|}{ PRODUCTO } \\
\hline Estadística & $\begin{array}{l}\text { Población } \\
\text { Vivienda }\end{array}$ & $\begin{array}{l}\text { Censos } \\
\text { Censos y Ministerio de } \\
\text { Vivienda y Urbanismo }\end{array}$ & $\begin{array}{l}\text { Cartografía con tendencias generales } \\
\text { de variación del parque habitacional de } \\
\text { departamentos* }\end{array}$ \\
\hline Observación & $\begin{array}{l}\text { Emplazamiento } \\
\text { Trayectorias y } \\
\text { experiencia }\end{array}$ & Elaboración propia & $\begin{array}{l}\text { Cartografías infográficas sobre formas } \\
\text { de emplazamiento de la urbanización y } \\
\text { formas de uso y ocupación del espacio }\end{array}$ \\
\hline Fotografía & $\begin{array}{l}\text { Fisonomía del } \\
\text { paisaje }\end{array}$ & Elaboración propia & $\begin{array}{l}\text { Registro y documentación visual de las } \\
\text { características paisajísticas }\end{array}$ \\
\hline
\end{tabular}

UN DEPARTAMENTO ES UNA VIVIENDA UBICADA DENTRO DE UN EDIFICIO DE, GENERALMENTE, 3 PISOS O MÁS

FUENTE: ELABORACIÓN PROPIA

Estas herramientas permiten obtener formas descriptivas de representación, capaces de dar cuenta de determinados aspectos de la sociedad (Becker, 2015). Es así que la densidad de la representación que podamos realizar sobre la producción de naturaleza en ciudades litorales chilenas va a depender tanto de la posibilidad de poner en relación diferentes dimensiones, como de la capacidad de estructurar una forma escritural que dé cuenta de la trama en la que está inserta.

\section{Urbanización y naturaleza en las ciudades litorales chilenas}

A través una descripción geohistórica, en este artículo se identifican procesos generales y tendencias actuales del modo en que la urbanización interactúa con la naturaleza; ello se aplica a dos ciudades donde, dada su condición costera, la morfología trazada por lo fluvial ha sido insoslayable: Coquimbo y Valparaíso. Al respecto, las preguntas planteadas son: ¿Cómo fueron sus transformaciones en el marco del advenimiento de la sociedad urbana? ¿Cómo se ha recreado la naturaleza borrada por la producción de entorno construido? 
FIGURA I | Superficie construida en Coquimbo y Valparaíso (2002-2019)

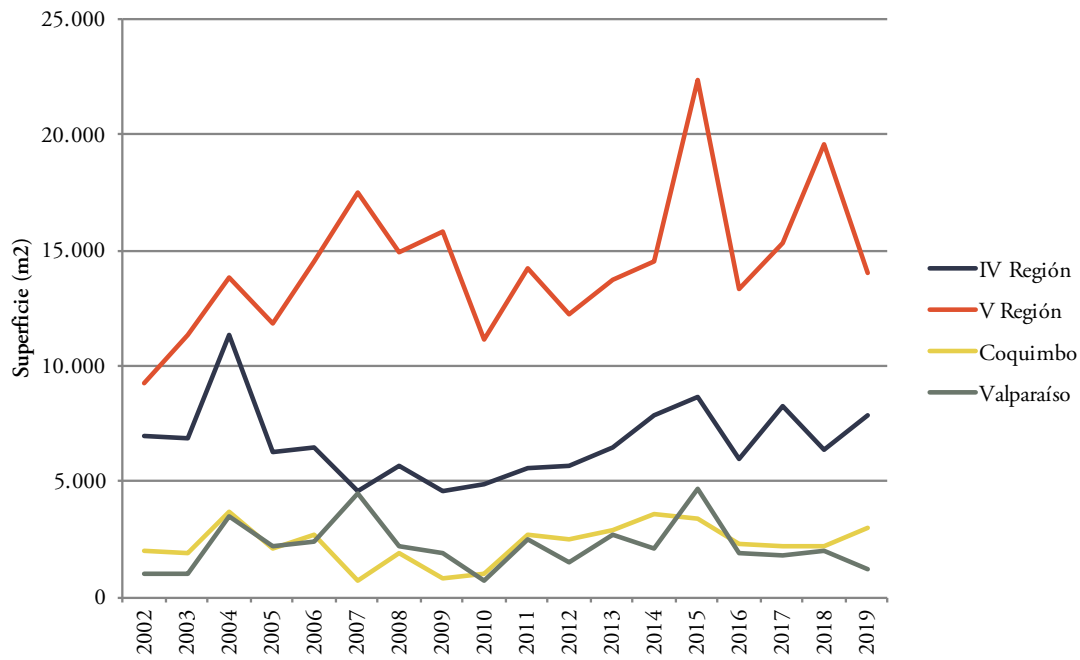

FUENTE: ELABORACIÓN PROPIA A PARTIR DE DATOS DEL MINISTERIO DE VIVIENDA Y URBANISMO (2OI9)

La Figura 1 muestra la superficie construida a escala regional y comunal para Coquimbo y Valparaíso. ${ }^{2}$ En términos generales, ambas comunas presentan similitudes cuantitativas en los últimos veinte años. Sin embargo, difieren en la composición de sus bases productivas. Coquimbo es una ciudad donde se concentra mayoritariamente la actividad portuaria, en conjunto con encadenamientos productivos vinculados al almacenaje y transporte, seguidos por la construcción y servicios. Esta base está determinada por la actividad minera, la cual otorga intensidad al actual proceso de urbanización (Daher, 2016; Rehner \& Rodríguez, 2017). En cuanto a Valparaíso, si bien también estuvo cruzado por la actividad minera, como metrópolis del salitre (Pinto, 1987), en la actualidad esta relación queda más bien supeditada a su función como puerto por donde se da salida a parte de la producción de la División Andina de la Corporación Nacional del Cobre (codelco). De acuerdo con lo planteado por Carroza y Valenzuela (2010) y por Ojeda y Pino (2019), la población económicamente activa de Valparaíso tiende a ocuparse en actividades vinculadas a los servicios, con un componente no menor de comercio informal.

Cabe destacar que las superficies totales de cada región corresponden a $15.396 \mathrm{~km}^{2}$ (Quinta Región de Valparaíso) y $40.580 \mathrm{~km}^{2}$ (Cuarta Región de Coquimbo), mientras que, en términos comunales, corresponden a $401 \mathrm{~km}^{2}$ y $1.429 \mathrm{~km}^{2}$, respectivamente. A esta escala, en Coquimbo, a través de la última actualización del Plan Regulador (Ilustre Municipalidad de Coquimbo, 2019), se propuso ampliar el límite urbano a 6.950 hectáreas, donde la superficie construida correspondería a 2.773 hectáreas, quedando una disponibilidad de 4.177 hectáreas de suelo disponible. De estos suelos disponibles, hay 3.449 hectáreas sin restricción y 738 están en zonas de riesgos no consolidadas (Ilustre Municipalidad de Coquimbo, 2019, p. 94). Por su parte, en Valparaíso el área urbana corresponde a 6.296 hectáreas, donde se ha definido un área de extensión urbana de 5.833 hectáreas, dejando un total de 18.778 de suelo no urbano (Ilustre Municipalidad de Valparaíso, 2019). 


\section{Valparaíso}

El origen de Valparaíso puede remontarse a su función como puerto oficial de Santiago (siglo XVI). A través de un asentamiento tipo caserío en torno a la iglesia de La Matriz, su población no creció significativamente hasta la consolidación de un mercado mundial, donde Chile se convirtió en un Estado asociado a la economía del salitre (Ortega, 2005). La condición de sitio desde el cual se emplazó corresponde a una morfología caracterizada por pliegues, quebradas, pendientes, honduras y una estrecha zona plana, configurada a partir de los recorridos del agua (Araya, 2009; Kapstein, 2009). El proceso de urbanización de Valparaíso implicó una reorganización espacial: a medida que la función portuaria se intensificaba, las fronteras naturales comenzaron a ser atravesadas de diferentes maneras. La población más desposeída empezó a instalar sus viviendas en laderas de quebradas, mientras la de mayores recursos económicos se instaló en las zonas planas y luego en lomas de algunos cerros (Olivares, 2018; Pino, 2015; Urbina, 2017). Paralelamente, las obras públicas trazaron la unificación tanto de la zona portuaria como de la conocida como El Almendral, mediante rellenos y ampliaciones hacia el territorio marítimo.

Para Martland (2017), el desarrollo urbano de Valparaíso puede comprenderse como una combinación entre ideales de progreso y de modernidad, realizados por agentes políticos públicos y privados mediante la aplicación de una tecnología orientada tanto al establecimiento de condiciones aptas para otorgar una mayor agilidad a las tasas de rotación de los capitales presentes, como al mejoramiento de la habitabilidad existente. En este marco, el control y manejo de las aguas fue clave. A principios de siglo xx fueron creados el lago Peñuelas y el tranque La Luz, ambos ubicados en Placilla de Peńuelas. El objetivo de la producción de estos espacios lacustres era otorgar agua potable y electricidad para tranvías y hogares, respectivamente.

A comienzos del siglo pasado, el avance del poblamiento cerro arriba implicó la necesidad de manejar la naturaleza existente en pos de adaptar zonas para el crecimiento poblacional. La construcción de desarenadores y la creación de bóvedas de piedra sobre los fondos de quebradas significaron un aumento del control de lo urbano (Araya, 2009). Para Álvarez (2001), estas fueron medidas sanitarias de corte higienista que impulsaron el proceso de urbanización de la ciudad (Figura 2). Sin embargo, no fueron las únicas: la consolidación de habitación en terrenos con pendientes se materializó mediante la creación de escaleras, callejones, calles y ascensores (Olivares, 2018; Urbina, 2017). Durante el siglo xx, las obras de urbanización continuaron desarrollándose bajo las lógicas de una ciudad que funcionaba en torno a lo portuario, lo industrial y lo comercial, donde el crecimiento y reorganización de su geografía social llevó al establecimiento de Viña del Mar como suburbanización (Cáceres \& Sabatini, 2007). El poblamiento en Valparaíso siguió el trazado de las líneas de cerro tanto mediante la aplicación de políticas de vivienda y la planificación de conjuntos urbanos, como a través de la urbanización informal, donde los rellenos han cobrado un papel preponderante tanto para la vivienda como para espacios destinados al ocio (Acosta \& Brignardello, 2014; Figueroa, Gutiérrez \& Vergara-Constela, 2019). 
FIGURA 2 | Esquema de urbanización en Valparaíso (siglos XIX-XXI)

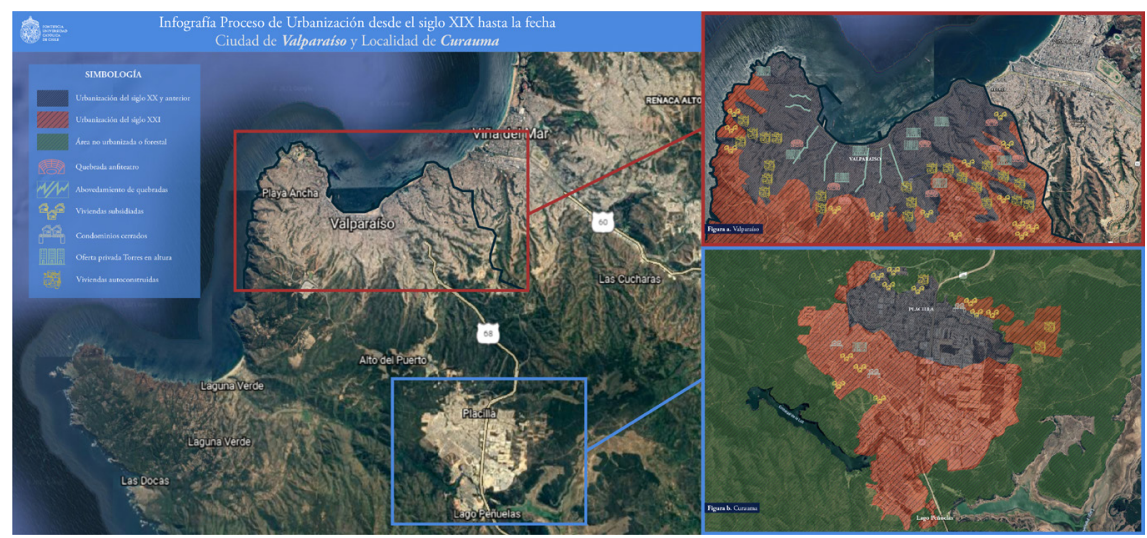

FUENTE: ELABORACIÓN PROPIA A PARTIR DE ARAYA (2009), MANSILLA Y FUENZALIDA (20IO), MARTLAND (20I7), URBINA (20I7) E HIDALGO, RODRÍGUEZ Y ALVARADO (2OI8)

En los últimos cuarenta años se han dado distintas formas de producción de espacio residencial en la región de Valparaíso, que atestiguan la articulación metropolitana en torno a la consolidación de la conurbación costera entre Viña del Mar y Concón, en conjunto con la conurbación interior de Quilpué, Villa Alemana y Limache (Borsdorf \& Hidalgo, 2005; Carroza \& Valenzuela, 2011; Fuentes \& Pezoa, 2018; Panez, 2015). A lo largo de este proceso, Valparaíso pasó de ser una ciudad relativamente compacta a convertirse en uno de los espacios centrales de una metrópolis de aproximadamente un millón de habitantes. Es en este marco donde podemos encontrar algunas de las diferentes formas en que se expresa la relación entre urbanización y naturaleza. Desde esta perspectiva, en las quebradas de la ciudad tiende a ubicarse la vivienda de autoconstrucción, la cual posee características predominantemente precarias tanto en su materialidad, como en las condiciones urbanas de habitabilidad (Pino, 2015). Estas viviendas se ubican mayormente en las partes altas de los cerros (Figura 3), aunque Carramińana (2015) ha mostrado que en el periodo intercensal 1992-2002, en las partes bajas de cerros relativamente centrales, como Cordillera, a medida que aumentaba el abandono de viviendas consolidadas, también aumentaba la urbanización precaria de quebradas contiguas.

La oferta privada, tanto de casas como de departamentos, ha tendido a concentrarse tanto en las zonas consolidadas (plan-centro, lomas de cerros) como en periferias interiores y márgenes de límites urbanos (Figura 4 y Figura 5). Algunos de los sectores donde se hace visible esta tendencia corresponden a los cerros Playa Ancha, San Roque, Delicias, Barón y Los Placeres. Allí, la nueva vivienda en altura se incorpora a antiguos predios boscosos o interviniendo directamente los ejes de quebrada. Esto significa una orientación de la producción residencial hacia la invención de un paisaje de la bahía de Valparaíso que no tenía precedentes en antiguos emplazamientos (Figura 4). Por otro lado, resulta preponderante el proyecto inmobiliario Curauma, ubicado en Placilla de Peńuelas, el cual se ha consolidado como espacio residencial con equipamiento como supermercados, bancos, bencineras, colegios, 
universidades, gimnasios y canchas deportivas (Mansilla \& Fuenzalida, 2010). Curauma tiende a promocionar su oferta como un modo de vida diseńado para nuevas familias jóvenes que desean vivir en un ambiente "natural", descontaminado y cercano a amenidades. Sin embargo, la urbanización de esta zona ha significado el aumento ingente del parque vehicular, la constante destrucción del bosque existente - predominantemente de pino, pero también con presencia de bosque esclerófiloy la progresiva colonización residencial del tranque La Luz.

FIGURA 3 | Vivienda autoconstruida. Quebrada Cabritería, Valparaíso

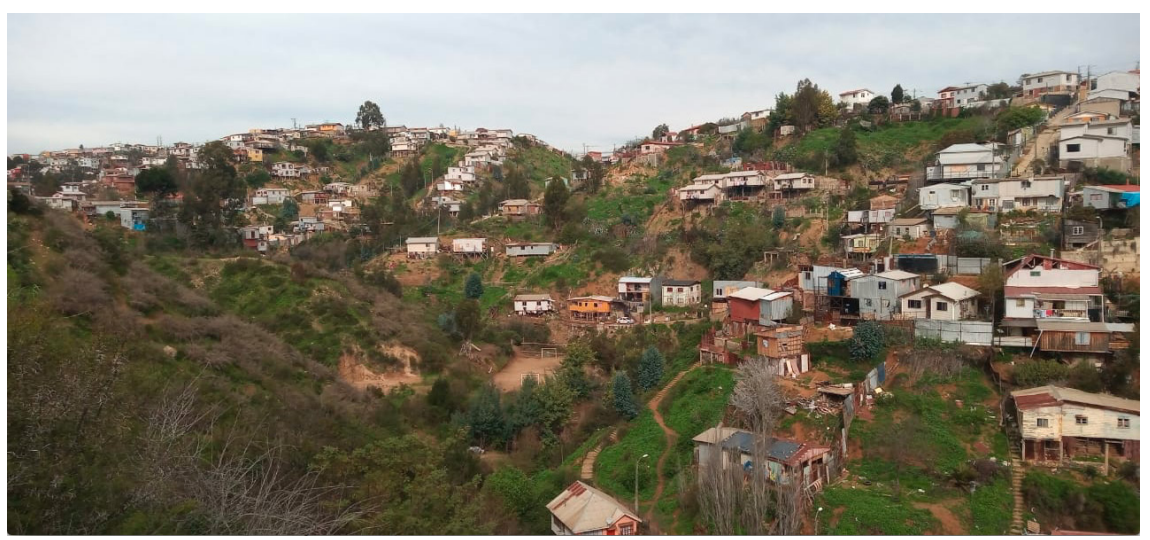

FUENTE: FOTOGRAFÍA DE LOS AUTORES

FIgURA 4 | Edificación en altura. Calle Ibsen, cerro Delicias, Valparaíso

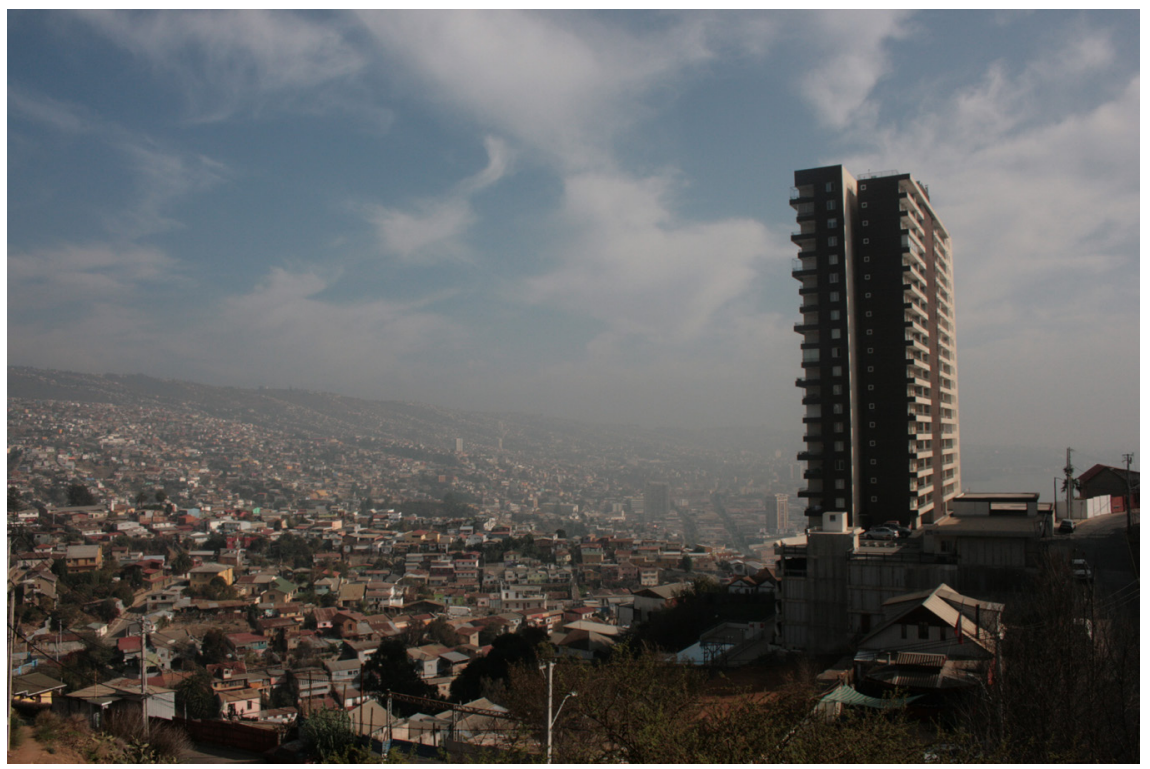

FUENTE: FOTOGRAFÍA CEDIDA POR MILENA BUSTOS MENESES 
FIGURA 5 | Diferencia porcentual de presencia de departamentos en Valparaíso (1992-2017)

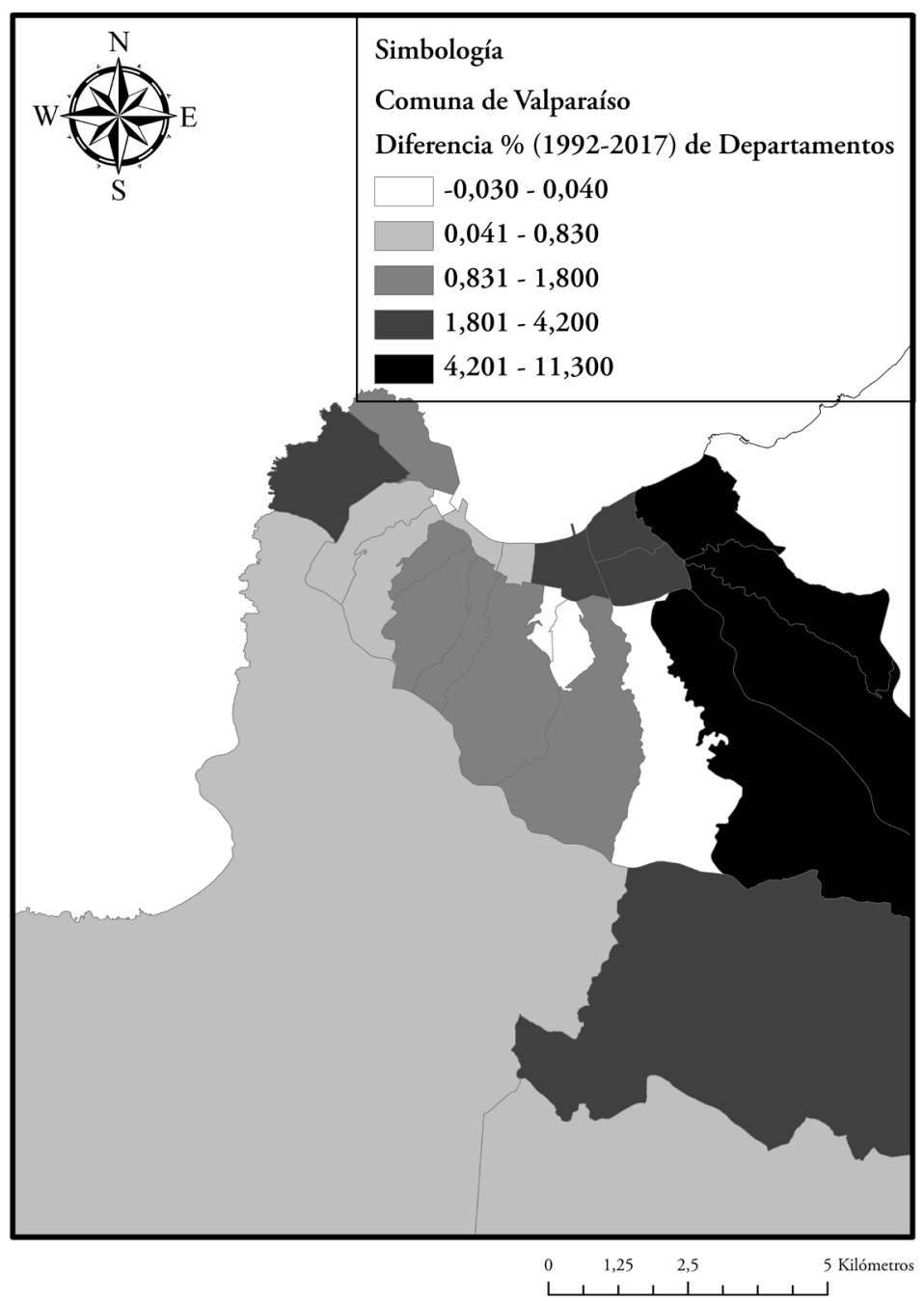

FUENTE: ELABORACIÓN PROPIA A PARTIR DE CENSOS DE POBLACIÓN Y VIVIENDA I 992 Y 2017

El caso de la vivienda subsidiada para las clases populares resulta interesante, puesto que la lógica de su localización se presenta de dos formas predominantes dentro de los márgenes urbanos (Figura 2). Por un lado, se identifica un emplazamiento en las últimas laderas del cerro Playa Ancha, contiguas a los acantilados Federico Santa María, es decir, en los últimos espacios disponibles para la urbanización, donde la amenidad de la vista al mar es contrarrestada por la dificultad de accesibilidad, la carencia de equipamiento y la adversidad climática del viento. Por otro lado, la 
tendencia indica que la vivienda subsidiada está siendo usada como punta de lanza para la extensión urbana. La realización de una serie de rellenos y cortes al cerro ha permitido la localización en las últimas zonas del límite urbano de la comuna, en cerros como La Cruz, Rocuant, Los Placeres o Rodelillo. Esto posibilita plantear la hipótesis de que la expansión urbana continuará en esa dirección. De hecho, lo que se desprende del instrumento metropolitano de planificación (Plan Regulador Metropolitano de Valparaíso [PREMvaL]) es precisamente aquello: la presión por urbanizar hacia Agua Santa, en Viña del Mar, o hacia el camino La Pólvora -que une el acceso sur del puerto de Valparaíso con el sector de Placilla-, lo que indefectiblemente apunta hacia la conurbación definitiva con Placilla y la estructuración de nuevos nichos de renta de suelo.

Un caso que merece mayor atención se ha producido en la localidad de Laguna Verde, en el litoral sur de la comuna. En la última década, es posible constatar un proceso de expansión urbana que se ha basado en una serie de loteos irregulares emplazados hacia el cerro en dirección de Curaumilla, los cuales carecen de infraestructura urbana (agua potable y alcantarillado), generando una constante degradación del medioambiente. Estos loteos no solo se basan en la construcción de habitaciones precarias, sino también de viviendas con un mayor nivel de consolidación, donde se entremezclan primera y segunda residencias.

\section{Coquimbo}

Desde mediados del siglo XIX, la ciudad de Coquimbo ha experimentado un importante crecimiento urbano al alero del puerto y de la construcción del ferrocarril en 1862. Esta infraestructura le dio vocación portuaria, que generó un centro urbano autónomo hasta el borde costero de la bahía de Coquimbo, antes de la quebrada de Peńuelas (Hidalgo, Arenas \& Monsalve, 2009). La arquitectura construida se caracterizó por la influencia anglosajona, indicador clave que denota la apertura de la ciudad a los mercados internacionales, principalmente debido al auge de la extracción de cobre, plata y manganeso desde el interior de la región. A fines del siglo XIX, la ciudad-puerto contaba con importantes muelles, zonas de acopio para el almacenaje de minerales, maestranza de ferrocarriles, servicios financieros y servicios públicos, como una aduana (Cerda, 2009; Espinoza, 1897). Desde el centro de la ciudad de Coquimbo, el tren se extendía hasta La Serena, atravesando humedales, esteros y quebradas; avanzaba hacia la mina Las Compañías y continuaba hacia el interior de la región, bordeando el río Elqui. Por el suroriente el tren llegaba hasta Ovalle, introduciéndose hacia el interior del continente, con ramales a Guayacán y Tongoy en el borde costero, conectando la cuenca de la región con la salida a estos pequeños puertos (Cerda, 2009). 
FIGURA 6 | Esquema de urbanización en Coquimbo (siglos XIX-XXI)

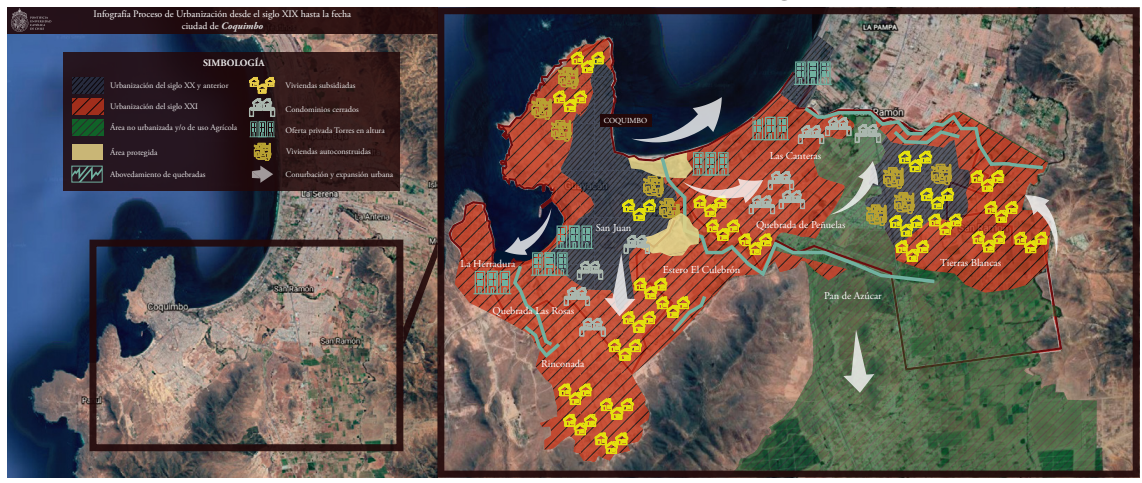

FUENTE: ELABORACIÓN PROPIA A PARTIR DE ORELLANA (2020) Y ORELLANA, DÍAZ Y FIERRO (2OI6)

\section{FIGURA 7 | Alto Coquimbo, Coquimbo}

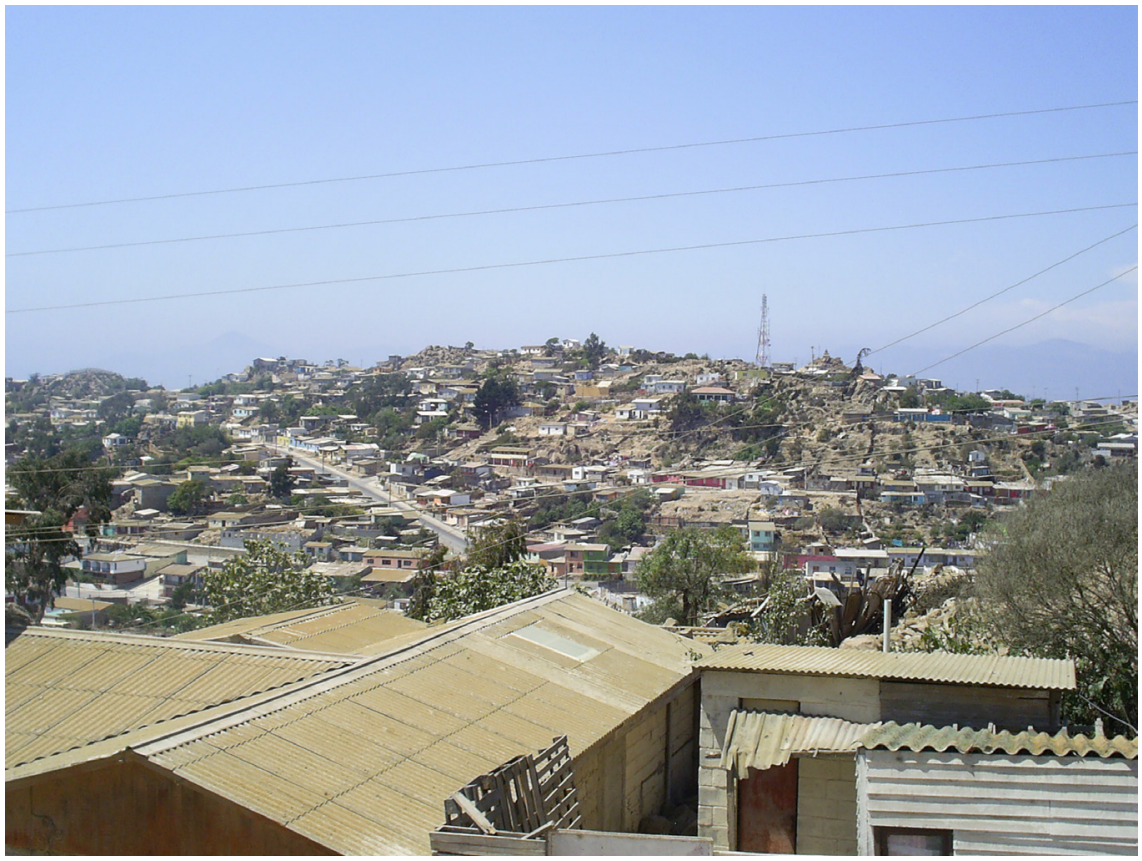

FUENTE: FOTOGRAFÍA DE LOS AUTORES

El poblamiento urbano se localizó en el sector puerto y se extendió hacia la península o parte alta de Coquimbo (Figura 6), caracterizada por pendientes, estructuras rocosas y un tejido urbano sinuoso (Cortés, 2017). A mediados de siglo xx, el Plan La Serena (1948-1952), impulsado por el presidente Gabriel González Videla (1975), desarrolló un trabajo de drenaje de aguas que desecó los "pantanos" ubicados desde la bahía de Coquimbo hasta Punta Teatinos en el norte de La Serena, 
ubicada en la primera terraza y en la actual Avenida Costanera de Coquimbo y Avenida del Mar de La Serena (Orellana, Díaz \& Fierro, 2016; Torrent, 2004; Ulricksen, 1952). El objetivo era la formación de parcelas y huertos de uso agrícola, los cuales se extendían en la zona de Peñuelas en Coquimbo y Las Vegas Sur en La Serena, cuestión que impulsó la migración de italianos para su colonización y producción agraria (González Videla, 1975; Napadensky \& Orellana, 2019). Hacia fines de la década de 1960, la frontera urbana de Coquimbo aún se establecía en los límites de la zona portuaria en la península, donde empezaba la zona de terrazas y las quebradas desde la Ruta 5 Norte hacia el oriente (Figura 7). Sin embargo, un sector de vivienda informal se formó alrededor del barrio industrial ubicado en la localidad de Tierras Blancas, en la tercera terraza al oriente del sector de Cantera Alta, lo que consigna un crecimiento disperso que se regularizó mediante planes de vivienda social en el camino que ingresa desde Ovalle por la Ruta 43, antiguo acceso a la ciudad (Orellana, 2020; Véliz, 1990).

FIGURA 8 | Diferencia porcentual de presencia de departamentos en Coquimbo (1992-2017)

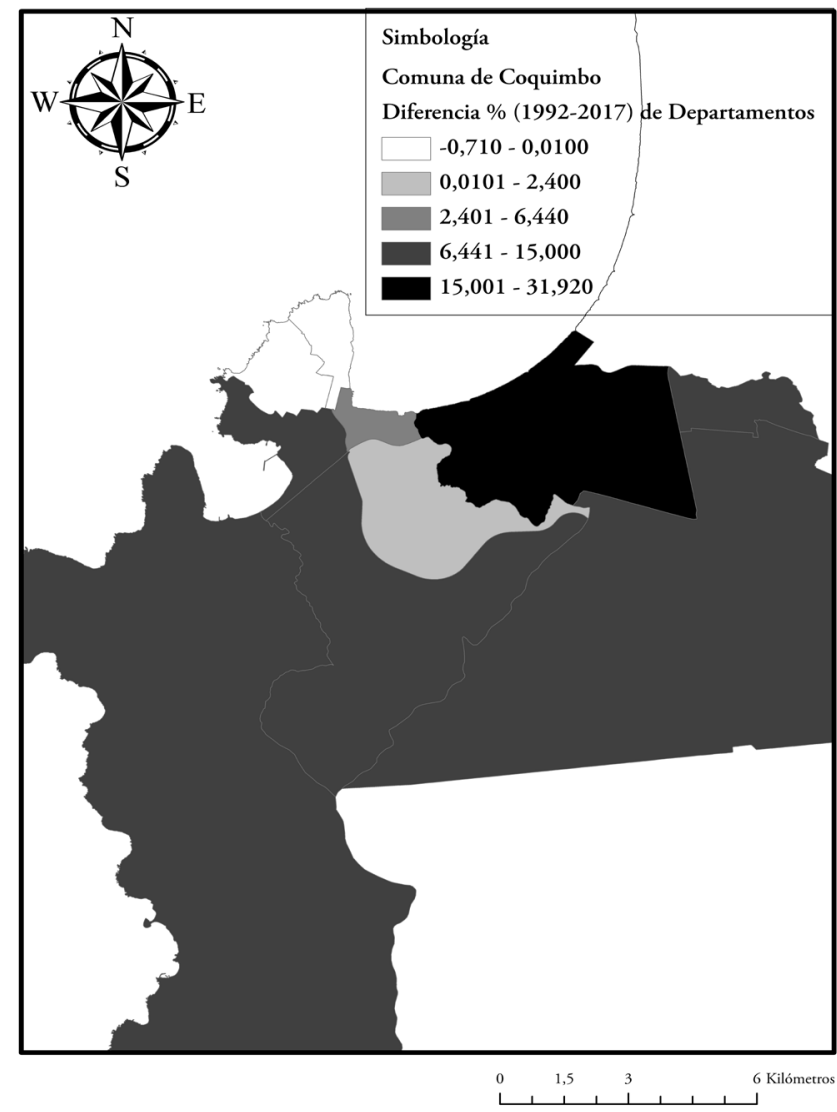

FUENTE: ELABORACIÓN PROPIA A PARTIR DE CENSOS DE POBLACIÓN Y VIVIENDA I 992 Y 20 I 7 
FIgURA 9 | Vivienda subsidiada en Las Canteras, Coquimbo

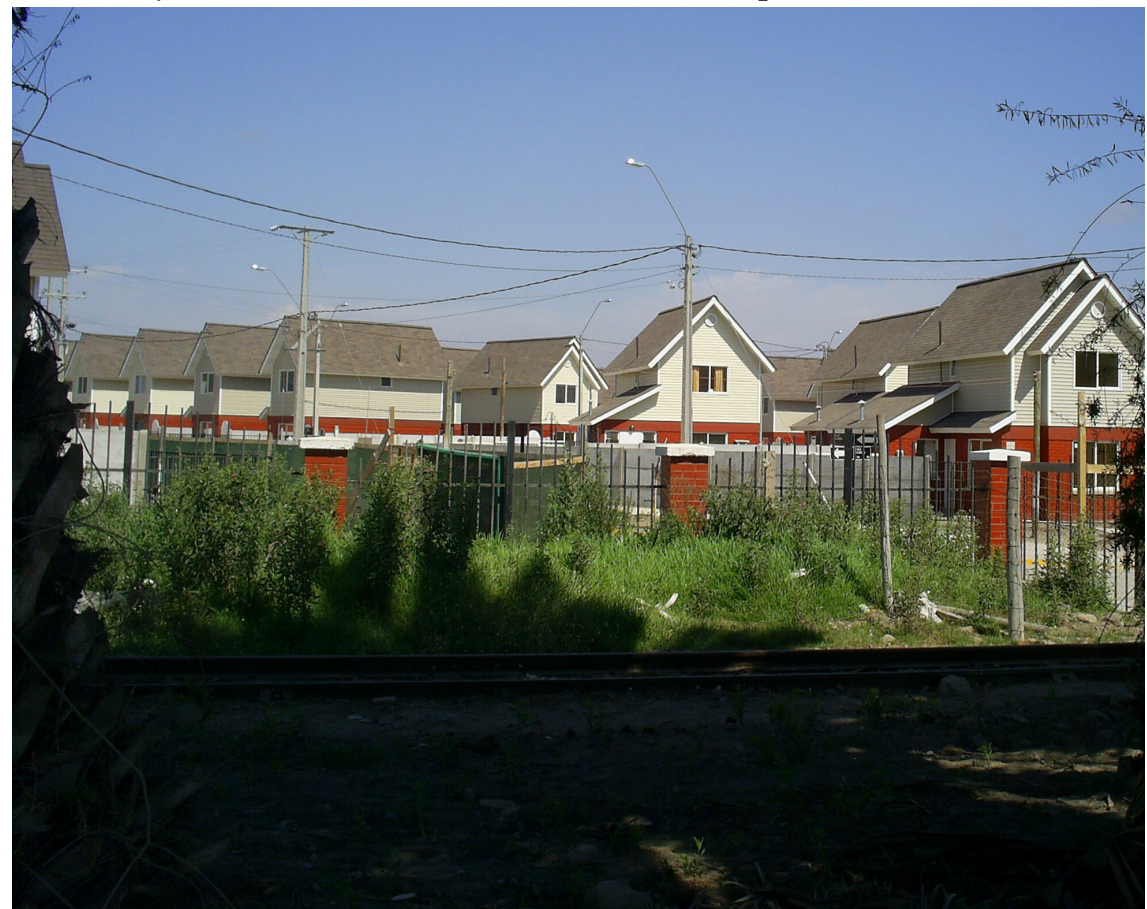

FUENTE: FOTOGRAFÍA DE LOS AUTORES

En la década de 1990, la tendencia de urbanización avanzó sobre pendientes y suelos agrícolas de Peńuelas y Las Canteras, proceso que impulsó la conurbación desde Coquimbo hacia La Serena (Figura 8). En el sector Las Canteras, los suelos de 5.000 metros cuadrados de uso agrícola fueron destinados a conjuntos habitacionales residenciales, con la subdivisión de los predios y la construcción de caminos de acceso (Orellana, Díaz \& Fierro, 2016). De la misma forma, las terrazas y quebradas del oriente de la ciudad comenzaron a urbanizarse a partir de conjuntos de vivienda social y privada, lo que fue desplazando la frontera urbana (Orellana, 2020).

Precisamente en esta zona se encuentra la microcuenca del estero El Culebrón, la que se desprende desde el interior de la región y desemboca en la bahía costera de Coquimbo, sistema natural que se encuentra inserto en el mismo espacio donde la ciudad se expande constantemente. El estero ha experimentado la presión de la ocupación humana, fundamentalmente asociada a vivienda informal, caminos, puentes, rellenos y microbasurales (Cerasa \& Martínez, 2007; Luna \& Mena, 2006; Rivera, Quiroz \& Arancibia, 2009). En la parte baja se encuentra la mayor intervención, asociada a la autopista 5 Norte, las canchas de fútbol del Club Atenas y la playa Changa. Allí se emplazan caminos de circulación donde se encuentra la toma de terrenos El Triángulo, ubicada en medio de líneas ferroviarias. En la zona alta por el sur, próximo a las quebradas del estero, se ubica el sector San Juan, construido a partir de rellenos y viviendas sociales en la década de 1970 (Cerasa \& Martínez, 
2007). Hacia el norte del estero se localiza Las Canteras, con lo que el avance de la producción inmobiliaria en la última década se aproxima a la ribera del estero (Luna \& Mena, 2006).

La década del 2000 vio el aumento de departamentos, muchos de ellos asociados a unidades de vivienda subsidiada (Figura 9) y a conjuntos inmobiliarios privados que se establecieron de forma fragmentada hacia el suroriente de la ciudad, en el sector Rinconada-El Sauce, produciendo rellenos en la quebrada Las Rosas y su cuerpo de agua, que desemboca en la denominada Playa Chica de La Herradura (Orellana, Díaz \& Fierro, 2016). De forma simultánea, en el borde costero, desde la quebrada de Peńuelas hacia el norte y la costa, que se desprende desde el centro de Coquimbo hacia el sur de la bahía La Herradura, se experimentó una fuerte transformación de la naturaleza con proyectos inmobiliarios de edificación en altura de primera y segunda residencia, los cuales se rentabilizan de acuerdo con el turismo, que releva las amenidades del borde costero y la vista al mar (Hidalgo, Arenas \& Monsalve, 2009; Napadensky \& Orellana, 2019; Segeur, 2015).

Según el actual Plan Regulador de la Comuna de Coquimbo (2019), el crecimiento urbano de la ciudad se orienta hacia el sur, incorporando zonas agrícolas e industriales ubicadas en el sector Pan de Azúcar en la Ruta 43, donde se encuentran emplazamientos de viviendas subsidiadas y condominios privados que han cambiado el uso de suelo. Además, la extensión propuesta hacia el sur, siguiendo la Ruta 5 Norte, establece el límite urbano en el espacio ubicado en el relleno sanitario El Panul, a ambos lados de la autopista, abarcando la totalidad de la península La Herradura hasta Punta Blanca Sur y produciendo con ello un nuevo escenario de urbanización futura.

\section{A modo de cierre: contradicciones y proyecciones en las ciudades litorales}

El estudio de la relación entre urbanización y naturaleza en América Latina necesita enfoques que puedan plantear una crítica al análisis funcional que se efectúa desde la gubernamentalidad neoliberal, como pueden ser los Objetivos de Desarrollo Sostenible (oDs) y la prescripción de metas con horizonte 2030, 2040 o 2050 (Organización de las Naciones Unidas, 2020). Obviamente, estos no son más que artefactos u objetos que se verifican en obras de mitigación o en las enunciaciones "verdes" y "sostenibles", según sea el tesauro que se ha definido para su diseño (Hidalgo, Alvarado \& Jiménez, 2017). Menos aún son dispositivos que puedan impugnar o contrarrestar el avance voraz del capitalismo, aunque se presenten como solución aparente a las contradicciones. Actualmente se requiere cuestionar de manera exhaustiva los límites y avances de la urbanización capitalista, considerando que la ciudad y sus ejes urbanizadores comprometen materias, flujos de energías e inversiones que, en su dinámica actual, aumentan las brechas entre las necesidades de la naturaleza y las del capital. Dicho de otro modo, la pregunta por el metabolismo y el avance de la urbanización abre una nueva veta a la crítica del capitalismo y su producción del espacio urbano.

Se ha pretendido comprender la especificidad de la urbanización en espacios costeros -fuertemente presionados por usos antrópicos e intensivos en capital, 
donde las geoformas están siendo modificadas constantemente no solo para acoger el emplazamiento humano, sino también para absorber excedentes y reinvertir capital-, sin algún resguardo de las restricciones que genera la interacción sociedadnaturaleza. Allí, en el marco de esa relación, la brecha de producción extractiva resulta a favor de la esfera humana. Como hemos visto, las ciudades de Coquimbo y Valparaíso han experimentado procesos de urbanización que interaccionan con la naturaleza de manera íntima. Ambas son ejemplos de urbanización litoral del área comprendida entre las zonas centro-norte y centro-sur del país, pero las lógicas de producción espacial y de naturaleza podrían ser extensibles a otras ciudades con otras condiciones de sitio similares. En ellas, la interacción metabólica es diferencial. Por ejemplo, entre la vivienda precaria y el medio natural donde se inserta, dicha relación al parecer resulta menos nociva que la que tiene lugar con la vivienda subsidiada o la oferta privada en altura. A pesar de constituir un paisaje mucho más precarizado, la materialidad de estas viviendas tiende a intervenir levemente el subsuelo o ser dispuesta para otros usos, a diferencia del impacto del cemento o de los grandes rellenos. Este paisaje se produce, entre otros asuntos, a partir de la histórica insuficiencia de canales para el acceso formal a la vivienda, el aumento demográfico y un imaginario que legitima la acción de la toma. Justamente es por medio de viviendas informales que quienes las habitan también ocupan un suelo inaccesible hasta entonces.

Si bien este tipo de urbanización se caracteriza por la precariedad de sus viviendas, a pesar de ello se han convertido en la punta de lanza de la urbanización secundada por la política de vivienda. Precisamente, la vivienda subsidiada es un factor clave como vector de urbanización, que opera mediante el drenado de humedales, cortes y rellenos de quebrada, constatando así que el subsidio entregado por el Estado va trazando y ocupando sitios donde dominaba la naturaleza. En contraste, en el borde costero de Coquimbo o en el plan, quebradas y cerros de Valparaíso, la localización de edificios privados en altura ha intensificado el uso y poblamiento de zonas centrales. Es en estos casos que la naturaleza es producida como amenidad; la invención del paisaje costero y/o playero es motivada por lo turístico o lo universitario, que va creando nuevos paisajes y nuevas vistas, a la vez que, paralelamente, interrumpe los caudales que desembocan en el mar. De este modo, es posible seńalar que en el contexto contemporáneo en que dominan los capitales financieros e inmobiliarios, el proceso de urbanización-costera ha generado cambios notables en la naturaleza existente de estas ciudades litorales.

En este marco, la producción de vivienda y edificación vertical avanza mediante la adecuación de los suelos, permitiendo verificar las tendencias urbano-globales, donde la implosión del borde-costero efectúa a la vez una explosión dispersa hacia cerros y valles. De este modo, la naturaleza ha sido recreada bajo un entramado mercantil-financiero donde es inventada por las estrategias de desarrollo y los discursos de amenidad, deseo y goce, que destruyen, modifican y producen tanto naturaleza como nuevos espacios residenciales. 


\section{Agradecimientos}

Los resultados mostrados en este artículo se enmarcan en la investigación FONDECYT Regular 1191555 "La producción de vivienda subsidiada en ciudades fluviales, marinas y lacustres en Chile: integración y sostenibilidad 2000-2017” y Proyecto de Investigación Conjunta ANID Chile - FAPESP Brasil 2019/13233-0 "Nature and urban metabolism in the restructuring production of space in Brazil and Chile".

\section{Referencias bibliográficas}

Acosta, H. \& Brignardello, A. (2014). 110 familias y un sueño. Historia y memoria de los primeros años de la Población María Eilers del Cerro Los Placeres de Valparaíso. Junta de Vecinos María Eilers, Valparaíso.

Alvarado, V. (2019). El bienestar en el Estado neoliberal: escenarios de la propiedad en el Gran Santiago. CUHSO-Cultura-Hombre-Sociedad, 29(2), 13-35. http://dx.doi. org/10.7770/0719-2789.2019.cuhso.04.a02

Álvarez, L. (2001). Origen de los espacios públicos en Valparaíso: el discurso higienista y las condiciones ambientales en el siglo xix. Revista de Urbanismo, (4), 1-22. http://dx.doi. org/10.5354/0717-5051.2011.11804

Araya, M. (2009). Las aguas ocultas de Valparaíso. $A R Q, 73,40-45$. http://dx.doi.org/10.4067/ S0717-69962009000300007

Becker, H. (2015). Para hablar de la sociedad, la sociología no basta. Siglo xxi Editores.

Bittar, L. (2016). A influência dos recursos naturais e dos aspectos físico-geográficos na configuração territorial da América do Sul. Ciência e Natura. Revista do Centro de Ciências Naturais e Exatas, 38(2), 716-721. http://dx.doi.org/10.5902/2179460X19116

Bodini, H. (1985). Geografía urbana. Instituto Geográfico Militar, Chile.

Boer, H. (2020). Europolders a European program on polder landscape, heritage, and innovation. En C. Hein (Ed.), Adaptive strategies for water heritage (pp. 231-251). Springer. https://doi.org/10.1007/978-3-030-00268-8_1210

Borsdorf, A. \& Hidalgo, R. (2005). Puerto Abierto ¡ciudad cerrada? Transformaciones socioespaciales en la estructura urbana del Área metropolitana de Valparaíso. Revista Geográfica de Valparaíso, 36, 189-206. https://bit.ly/3mWhEXz

Cáceres, G. \& Sabatini, F. (2007). Suburbanización y segregación urbana en el Chile decimonónico: hipótesis sobre la formación histórica del Gran Valparaíso. En J. Valenzuela (Ed.), Historias urbanas. Homenaje a Armando de Ramón (pp. 93-122). Ediciones Universidad Católica de Chile.

Carramiñana, P. (2015). Los imaginarios urbanos y el uso social del espacio barrial. El caso del barrio de Cordillera Central del cerro Cordillera de Valparaiso. Tesis para optar al grado de Licenciado en Sociología y el Título Profesional de Socióloga. Universidad de Valparaíso, Chile. 
Carroza, N. \& Valenzuela, F. (2010). Transformaciones en el mercado del trabajo y expresión territorial de las desigualdades sociales: el caso del área metropolitana de Valparaíso. Revista LIDER, 12(17), 119-136. https://revistaliderchile.com/index.php/liderchile/ article/view/152

Carroza, N. \& Valenzuela, F. (2011). Mercados de trabajo y reconfiguración metropolitana: nuevas desigualdades socio-territoriales. El caso del área metropolitana de Valparaíso. En G. Bailey, N. Carroza, F. Espinoza \& R. Tiemann (Eds.), Valparaíso en tránsito. Perspectivas desde una nueva sociología de la ciudad (pp. 44-69). El Topo.

Castro, C. (2015). Geografía de las dunas costeras de Chile. Instrumentos y pautas para su manejo integrado. Ediciones uc.

Castro, C. \& Hidalgo, R. (2002). Del pueblo balneario a la gran conurbación: la expansión urbana en el litoral central de la v Región de Valparaíso, Provincia de San Antonio, 1954-2000. Revista Geográfica de Valparaíso, (32-33), 91-103.

Cerasa, M. \& Martínez, L. (2007). Determinación de impactos ambientales causados por el desarrollo urbano en el estero El Culebrón, iv Región, Chile. Aplicando metodología SIG. Memoria para optar al grado de Ingeniero en Prevención de Riesgos y Medioambiente. Facultad de Ciencias del Mar, Universidad Católica del Norte, Chile.

Cerda, P. (2009). El ferrocarril Coquimbo-La Serena y la industria del cobre 1862-1895. En L. Ortega, M. Godoy \& H. Venegas (Eds.), Sociedad y minería en el Norte Chico, 18401930 (pp. 125-149). Universidad Academia de Humanismo Cristiano / Universidad de Santiago de Chile.

Cortés, L. (2017). El pericentro de Coquimbo como escenario de renovación estratégica. Revista AUS [Arquitectura / Urbanismo / Sustentabilidad], 19, 10-17. http://dx.doi. org/10.4206/aus.2016.n19-03

Daher, A. (2016). Metropolización en la región de mayor crecimiento de Chile, Coquimbo. Revista AUS [Arquitectura / Urbanismo / Sustentabilidad], 19, 45-50. http://dx.doi. org/10.4206/aus.2016.n19-08

de Mattos, C. (2006). Modernización capitalista y transformación metropolitana en América Latina: cinco tendencias constitutivas. En A. Geraiges, M. Arroyo \& M. L. Silveira (Comps.), América Latina: cidade, campo e turismo (pp. 41-63). CLACso / Universidade de São Paulo.

Espinoza, E. (1897). Jeografía descriptiva de la República de Chile. Encuadernación Barcelona. http://www.memoriachilena.gob.cl/602/w3-article-8110.html

Figueroa, D., Gutiérrez, D. \& Vergara-Constela, C. (2019). A puro ñeque. Memoria histórica de la población Cincel del cerro Los Placeres de Valparaíso. Victorino Laynez.

Fuentes, L. \& Pezoa, M. (2018). Nuevas geografías urbanas en Santiago de Chile 1992-2012. Entre la explosión y la implosión de lo metropolitano. Revista Geografía Norte Grande, (70), 131-151. http://dx.doi.org/10.4067/S0718-34022018000200131

González Videla, G. (1975). Memorias. Editora Nacional Gabriela Mistral. http://www. memoriachilena.gob.cl/602/w3-article-8770.html.

Gray de Cerdán, N. (1987). Territorio y urbanismo. Universidad Nacional de Cuyo (UnCuYo), Mendoza.

Harvey, D. (2012). El enigma del capital y las crisis del capitalismo. Akal.

Harvey, D. (2014). Diecisiete contradicciones y el fin del capitalismo. Instituto de Altos Estudios Nacionales (IAEN), Quito. 
Hidalgo, R. (2005 [1950]). La vivienda social y la construcción del espacio urbano en el Santiago del siglo XX. Instituto de Geografía PuC - Centro de Investigaciones Diego Barrios Arana. http://www.centrobarrosarana.gob.cl/622/articles-56376_archivo_01.pdf

Hidalgo, R., Alvarado, V. \& Jiménez, V. (2017). Una máquina con rostro humano. Estructura urbana residencial y neoliberalismo en Chile: construyendo propiedad de suelo y vivienda (1990-2015). En A. Ferreira, J. Rúa \& R. de Mattos (Eds.), O espaço e a metropolização. Cotidiano e ação (pp. 391-408). Consequência.

Hidalgo, R., Alvarado, V. \& Santana, C. (2016). Mitos, ideologías y utopías neoliberales de la producción de espacio. Hacia una agenda de investigación alternativa. En R. Hidalgo, D. Santana, V. Alvarado, F. Arenas, A. Salazar, C. Valdebenito \& L. Álvarez (Eds.), Las costas del neoliberalismo: Naturaleza, urbanización y producción inmobiliaria. Experiencias en Chile y Argentina (pp. 24-66). Serie geolibros 23, Instituto de Geografía, Pontificia Universidad Católica de Chile - Instituto de Geografía, Pontificia Universidad Católica de Valparaíso.

Hidalgo, R., Arenas, F. \& Monsalve, F. (2009). La conurbación La Serena-Coquimbo: problemas y desafíos de su transformación metropolitana. En R. Hidalgo, F. Arenas \& C. de Mattos (Eds.), Chile: del país urbano al país metropolitano (pp. 161-184). Serie Geolibros 12, Instituto de Geografía, Colección eure-Libros, Instituto de Estudios Urbanos y Territoriales, Pontificia Universidad Católica de Chile. http://geografia. uc.cl/images/serie_GEOlibros/del_pais_urbano/Hidalgo_Arenas_Monsalve.pdf

Hidalgo, R., Camus, P., Alvarado, V., Paulsen-Espinoza, A. \& Olea, J. (2016). Aguas de ficción a la carta: la producción de naturaleza como nicho de renta. Bienes comunes y espacio urbano exclusivo en torno a las crystal lagoons. En C. Alvarado, R. Gómez \& R. Hidalgo (Eds.), Expresión territorial de la fragmentación y segregación (pp. 13-30). Praxis Digital 9 - Universidad Autónoma del Estado de Morelos, México.

Hidalgo, R., Rodríguez, V. \& Alvarado, V. (2018). Arriba del cerro o sobre el humedal: producción de naturaleza y expansión inmobiliaria en ciudades marinas y fluviales. El caso de Valparaíso y Valdivia, Chile. Revista Diálogo Andino, (56), 87-100. http:// dx.doi.org/10.4067/S0719-26812018000200087

Hidalgo, R., Rodríguez, L., Paulsen-Espinoza, A. \& Alvarado, V. (2018). La naturaleza como obstáculo: perspectivas críticas del avance de la vivienda social e infraestructura vial sobre los humedales en la ciudad de Valdivia. Investigaciones Geográficas, (56), 27-44. http://dx.doi.org/10.5354/0719-5370.2018.48409

Ilustre Municipalidad de Coquimbo. (2019). Memoria explicativa. Actualización Plan Regulador de Coquimbo. https://www.municoquimbo.cl/images/estructura/Plano\%20 Regulador\%20Secplan/1_Memoria\%20Explicativa_Junio_2019.pdf

Ilustre Municipalidad de Valparaíso. (2019). PLADECO 2019-2030. https://www. municipalidaddevalparaiso.cl/archivos/2019/PLADECO/PROPUESTA_ PLADECO_2019.pdf

Kapstein, G. (2009). Ciudad anfiteatro. $A R Q$, (73), 23-27. http://dx.doi.org/10.4067/S071769962009000300004

Lefebvre, H. (1974). La producción del espacio. Papers. Revista de Sociologia, 3, 219-229. https://doi.org/10.5565/rev/papers/v3n0.880

Lefebvre, H. (1976). Espacio y politica. Península.

Lefebvre, H. (2013). El pensamiento marxista y la ciudad. Editorial Coyoacán. 
Lefebvre, H. (2015). De lo rural a lo urbano. Taller Praxis.

Luna D. \& Mena, S. (2006). Zonificación para el manejo ambiental del Estero el Culebrón. Municipalidad de Coquimbo, proyecto "Ciudad y conocimiento". I. Municipalidad de Coquimbo.

Madden, D. \& Marcuse, P. (2019). En defensa de la vivienda. Capitán Swing.

Mansilla, P. \& Fuenzalida, M. (2010). Procesos de desarrollo urbano-regional y exclusión territorial: Nuevas formas de urbanización en el área metropolitana de Valparaíso. Estudio de caso ciudad de Curauma. Revista INVI, 25(69), 103-123. http://dx.doi. org/10.4067/S0718-83582010000200003

Martínez, C. (2014). Factores de vulnerabilidad y Reconstrucción post terremoto en tres localidades costeras chilenas: ¿generación de nuevas áreas de riesgo? Bulletin de L'Institut Francais d'Etudes Andines, 43(3), 529-558.

Martland, S. (2017). Construir Valparaíso. Tecnología, Municipalidad y Estado 1820-1920. Centro de Investigaciones Diego Barrios Arana. https://www.academia.edu/42836064/ Construir_Valpara\%C3\%ADso_Tecnolog\%C3\%ADa_municipalidad_y_ estado_1820_1920

Mautner, Y. (1999). A periferia como fronteira de expansão do capital. En C. Deak \& S. Ramos (Eds.), O processo de urbanização no Brasil (pp. 245-259). Edusp (Editora da Universidade de São Paulo).

Mayol, A. (2012). El derrumbe del modelo. Lom.

Mayol, A. (2019). Estallido social. Modelo derrumbado. Sociedad rota. Politica inútil. Catalonia.

Ministerio de Vivienda y Urbanismo (MINVU). (2019). Observatorio Habitacional. Estadísticas anuales de edificación aprobada. Santiago, Chile.

Napadensky, A. \& Orellana, A. (2019). Atractivos paisajísticos y dispersión de grupos medios de altos ingresos ¿Una nueva elite de consumidores experienciales? El caso del Gran La Serena y el Gran Concepción 1965-2012. Revista 180, (43), 101-114. http://dx.doi. org/10.32995/rev180.num-43.(2019).art-608

Ojeda, L. \& Pino, A. (2019). Valparaíso y su comercio callejero: ¿¿Espacialidad esporádica y/o espacialidad saturada? AUS [Arquitectura / Urbanismo / Sustentabilidad], (25), 11-19. https://doi.org/ 10.4206/aus.2019.n25-03

Olivares, N. (2018). Valparaiso. Estudio del proceso de poblamiento de sus quebradas y cerros, 1536-1990. Ediciones Universitarias de Valparaíso.

Orellana, A. (2020). Conformación metropolitana desde la fragmentación: el proceso de conurbación del Gran La Serena. Revista Urbano, 23(41), 58-83. https://doi.org/10.2 2320/07183607.2020.23.41.04

Orellana, A., Díaz, M. \& Fierro, T. (2016). De ciudad mediterránea a metrópolis costera: el caso del Gran La Serena. Revista Urbano, 19(33), 30-43. http://revistas.ubiobio.cl/ index.php/RU/article/view/2287

Organización de las Naciones Unidas. (2020). Objetivos y metas del desarrollo sostenible. https:// www.un.org/sustainabledevelopment/es/cities/

Ortega, L. (2005). Chile en la ruta al capitalismo. Cambio, euforia y depresión. 1850-1880. Centro de Investigaciones Diego Barrios Arana - LOM. 
Panez, A. (2015). Desarrollo metropolitano del Gran Valparaíso en debate: divergencias entre discursos y prácticas espaciales de actores políticos. Revista de Geografía Valparaiso (en línea), (51), 112-132. https://www.pucv.cl/uuaa/site/docs/20180316/201803161728 43/51_7.pdf

Pereira, X. (2005). Dinâmica sócio-espacial e metamorfoses da periferia na transformaçáo de São Paulo. En R. Hidalgo, R. Trumper \& A. Borsdorf (Eds.), Transformaciones urbanas $y$ procesos territoriales. Lecturas del nuevo dibujo de la ciudad latinoamericana (pp. 187199). Serie geolibros 4, Instituto de Geografía, Pontificia Universidad Católica de Chile.

Pino, A. (2015). Quebradas de Valparaíso. Memoria social autoconstruida. LOM.

Pinto, J. (1987). Valparaíso metrópolis financiera del boom del salitre. En S. Lorenzo (Comp.), Valparaíso, 1536-1986. Primera jornada de Historia Urbana (pp. 119-134). Instituto de Historia, Pontificia Universidad Católica de Valparaíso.

Programa de las Naciones Unidas para el Desarrollo (PNUD). (1998). Las paradojas de la modernización. Desarrollo humano en Chile 1998. https://www.cl.undp.org/content/ chile/es/home/library/human_development/las-paradojas-de-la-modernizacion.html

Ramas, C. (2015). Fetiche y mistificación capitalistas. Siglo xxi Editores.

Reclus, E. (1975 [1905]). El hombre y la tierra. Doncel.

Rehner, J. \& Rodríguez, S. (2017). Dinámicas inmobiliarias en ciudades del norte y sur de Chile. En Anales de la Sociedad Chilena de Ciencias Geográficas 2016 (pp. 249-262). Santiago de Chile.

Rehner, J., Rodríguez, S. \& Murray, W. (2018). Ciudades en auge en Chile: rol de la actividad exportadora en la dinámica del empleo urbano. Revista EURE - Revista de Estudios Urbano Regionales, 44(131), 151-171. http://dx.doi.org/10.4067/S025071612018000100151

Rivera, L., Quiroz, S. \& Arancibia, J. (2009). Propuesta de Plan Integral de restauración del Humedal El Culebrón, Región de Coquimbo. Comisión Nacional de Medio Ambiente, Chile.

Rojas, C., Munizaga, J., Rojas, O., Martínez, C. \& Pino, J. (2019). Urban development versus wetland loss in a coastal Latin American city: Lessons for sustainable land use planning. Land Use Policy, 80, 47-56. https://10.1016/j.landusepol.2018.09.036

Rojo Mendoza, F., Jara, T. \& Frick, J. (2019). Las urbanizaciones cerradas en la ciudad intermedia. El caso de Temuco (Chile), 2005-2014. Bitácora Urbano Territorial, 29(1), 79-90. https://doi.org/10.15446/bitacora.v29n1.63192

Santana, D. (2018). Introducción a los metromarxismos geográficos latinoamericanos: perspectivas sobre la ciudad, lo urbano y la urbanización. Cuadernos de Vivienda y Urbanismo, 11(22), 1-20. https://doi.org/10.11144/Javeriana.cvu11-22.imgl

Santana, D. (2019). La teoría de lo inmobiliario más allá de la "vieja cuestión urbana": bases para una economía política del espacio social. En D. Santana, V. Alvarado \& R. Hidalgo (Eds.), Las geografías del neoliberalismo en América del Sur. Ensayos descriptivos, criticos y necesarios (pp. 230-262). Serie Geolibros 30, Instituto de Geografía, Pontificia Universidad Católica de Chile.

Santos, M. (1990). Por una geografia nueva. Espasa-Calpe. 
Segeur, S. (2015). Nuevas urbanizaciones costeras, ¿gentrificación turística en la Bahía de Coquimbo? Revista de Urbanismo, (32), 18-31. http://dx.doi.org/10.5354/07175051.2015 .36528

Smith, N. (2020). Desarrollo desigual. Naturaleza, capital y la producción del espacio. Traficantes de Sueños.

Sugranyes, A. (2005). La política habitacional en Chile, 1980-2000: un éxito liberal para dar techo a los pobres. En A. Rodríguez \& A. Sugranyes (Eds.), Los con techo. Un desafio para la política de vivienda social (pp. 23-58). Ediciones Sur.

Torrent, H. (2004). Patrimonio territorial y arquitectónico: El Plan Serena. Revista Urbano, 7(10), 93-99. http://revistas.ubiobio.cl/index.php/RU/article/view/532/495

Ulricksen, G. (1952). Bases para la planeación regional del Norte Chico. Provincias de Atacama y Coquimbo (Región de los Valles Transversales). Tesis en Planeamiento para optar al título profesional de Arquitecto. Universidad de Chile. https://revistaurbanismo.uchile.cl/ index.php/RU/article/download/247/209/

Urbina, M. (2017). La colonización vertical de Valparaíso. Etapa inicial. HYBRIS, 7, 97-127. http://10.5281/zenodo.58621

Véliz, G. (1990). Conurbación La Serena-Coquimbo: tendencias en el uso del suelo. Revista Geográfica, (111), 219-258. https://www.jstor.org/stable/40992612

Vergara-Perucich, J. (2018). Aplicaciones de la teoría implosión/explosión: relación entre la Región Metropolitana de Santiago de Chile y los territorios productivos regionales. Revista EURE - Revista de Estudios Urbano Regionales, 44(133), 71-90. http://dx.doi. org/10.4067/s0250-71612018000300071

Zusman, P. (2014). La descripción en geografía. Un método, una trama. Boletín de Estudios Geográficos, (102), 135-149. https://siip2019-2021.bdigital.uncu.edu.ar/objetos_ digitales/6811/007-zusman-beg-102.pdf 